\title{
HISTÓRIA E DESENVOLVIMENTO DA ATIVIDADE PESQUEIRA NO \\ LITORAL NORTE DO RIO GRANDE DO SUL (SÉCULO XVII - XX)
}

\author{
HISTORY AND DEVELOPMENT OF THE FISHING ACTIVITY IN \\ THE NORTH COASTLINE OF RIO GRANDE DO SUL (FROM XVII TO \\ XX CENTURY)
}

\author{
Lucas Antonio da Silva \\ Mestre - Professor na UFPel \\ E-mail: lucas_vc1@hotmail.com
}

\begin{abstract}
RESUMO: A pesca no litoral do Rio Grande do Sul é uma atividade desenvolvida desde o início da ocupação dessa região. Contudo, os registros mais consistentes da pesca, conhecidos por arqueólogos, são os Sambaquis. Estes apresentam uma série de artefatos característicos para a realização dessa atividade, como, por exemplo, anzóis, pesos de rede, etc. A partir da colonização portuguesa, pouco se conhece sobre a pesca no litoral sul riograndense, nem sobre a existência de grupos de pescadores na costa e o desenvolvimento dessas comunidades. Portanto, este estudo tem como objetivo compreender o desenvolvimento da atividade pesqueira no litoral norte do Rio Grande do Sul, assim como evidenciar os principais fatores que levaram ao desenvolvimento das comunidades pesqueiras da região.
\end{abstract}

PALAVRAS-CHAVE: Pesca. Litoral. Viajantes.

ABSTRACT: Fishing in the coastline of Rio Grande do Sul is an activity that has been developed since the beginning of this region colonization. However, the most consistent fishing records, known by archaeologists, is called The Sambaquis. These ones offer a serie of manufactured goods characteristic to the accomplishment of this activity, as for instance fish hook, fish net weight, etc. From the Portuguese colonization on, little is known about fishing in the South Brazil coastline, even about the existence of fishermen groups in the coastline and the development of those communities. Therefore, this study has as its principal objective understand the development of the fishing activity in the north coastline of Rio Grande do Sul, as well as to highlight the main factors that enduced to the development of the fishing communities of the region.

KEYWORDS: Fishing. Coastline. Travelers.

\section{Introdução}

O presente artigo tem por objetivo compreender o desenvolvimento da atividade pesqueira no litoral norte do Rio Grande do Sul. Através de relatos de viagem, buscou-se evidenciar as origens e a fixação de comunidades pesqueiras nessa região. A observação etnográfica, conduzida ao longo da pesquisa de mestrado (SILVA, 2012), possibilitou a 
compreensão das relações que se estabelecem entre os pescadores e o desenvolvimento dos balneários marítimos, que viabilizaram a comercialização do pescado na região.

Contudo, mesmo com a proposta de compreender o desenvolvimento da atividade pesqueira no litoral norte do Rio Grande do Sul, por vezes fez-se necessária a referência dessa atividade em outras regiões do Estado. Isso porque, até meados do século XIX, não foi possível verificar informações consistentes sobre o desenvolvimento da atividade pesqueira em uma região tão restrita quanto o litoral norte. Sendo assim, foram utilizadas as informações referidas pelos viajantes de experiências advindas de suas passagens pela região para complementar o registro sobre a pesca na época destacada.

Por fim, deve-se destacar, também, que inúmeras pesquisas arqueológicas, desde o final do século XIX, vêm contribuindo para a compreensão da pré-história da pesca no Rio Grande do Sul. Sabe-se, desde esta época, da existência de sítios arqueológicos e de grupos pré-históricos adaptados ao ambiente costeiro, pois a existência de inúmeros vestígios ligados à pesca, como, por exemplo, anzóis, pesos de rede, ossos de peixes, etc., indicam uma ocupação especializada nesse ambiente. Os sambaquis, sítios arqueológicos presentes em grande parte da costa brasileira, caracterizados pela cultura material em análise, são os vestígios mais consistentes dessa ocupação pesca-coletora em nosso litoral.

\section{Os primeiros relatos do litoral (século XVII e XVIII)}

A partir do descobrimento do Brasil, em 1500, o litoral passou a receber uma série de viajantes que almejam fazer um reconhecimento do território. Uma das mais conhecidas expedições de reconhecimento do litoral foi empreendida por Martim Afonso de Souza em 1531. Percorrendo a costa sul-brasileira, Afonso identificou os principais acidentes geográficos ao longo do litoral gaúcho, como, por exemplo, o rio Mampituba, o rio Tramandaí e a barra da Lagoa dos Patos. Segundo Soares e Purper (1985), após essa primeira expedição, foi mais de meio século de abandono completo do litoral gaúcho. No entanto, deve-se destacar que, neste primeiro período, a ocupação do litoral se caracterizava pela presença de grupos indígenas, como os Guaranis e os Jês. Através dos vestígios arqueológicos presentes nos sítios é possível afirmar que esses grupos também praticavam a pesca na região. 
Conforme propôs César (1981), as crônicas de viagem podem ser divididas, no Rio Grande do Sul, em quatro categorias ${ }^{1}$ em ordem cronológica. São elas: o indígena e a catequese, de 1605 a 1663; as tentativas de povoamento, de 1698 a 1725; a fundação do Rio Grande de São Pedro, em 1737; e, por fim, a terra de ninguém a terra de muitos, de 1737 a 1801.

O primeiro período iniciou-se com a expedição jesuítica de Jerônimo Rodrigues em 1605, que, conforme César (1981), foi o primeiro contato dos portugueses com os indígenas do litoral do Rio Grande do Sul. A expedição tinha por objetivo iniciar uma missão para a catequese dos índios da região, no entanto, a missão não obteve resultado significativo, sendo abandonada após alguns meses. Durante o período em que ficou no litoral, o jesuíta fez muitas observações sobre o comportamento dos indígenas da região, sobretudo com relação aos hábitos alimentares e ao modo como viviam:

Nem comer comem por gosto, senão por encher a barriga. E, assim todos têm dentes danados por comer tudo quentíssimo e cheio de areia. Não comem mingau, nem pimentas, nem juquifaia, nem sal, com estarem junto do mar, e se lhe dão do reino, comem-no. [...] E é o peixe de cá ordinariamente tão magro que se o lançarem a uma pedra pegara. (CÉSAR, 1981[RODRIGUES, 160507], p.25)

A segunda crônica em destaque foi a de Pedro Simão de Vasconcelos, que, percorrendo o litoral da Cananéia até Maldonado (Uruguai), descreveu os acidentes geográficos ao longo de sua jornada, citando o rio Martim Afonso, posteriormente conhecido como rio Tramandaí, e a população indígena que habitava a região, os Carijós. Sendo assim, esse primeiro período foi marcado pelo reconhecimento da costa sul rio-grandense, por isso as crônicas dessa época estão permeadas de descrições do território e das populações da região.

O segundo período, chamado de tentativas de povoamento, estendeu-se de 1698 a 1725 (César, 1981) e foi caracterizado por uma exploração maior do território. Existe uma preocupação dos cronistas de encontrar recursos naturais e rotas terrestres até o Rio da Prata. Entre esses autores do período, destacaram-se Domingos Filgueira (1703), que tinha como objetivo, na sua crônica, indicar a melhor forma de viajar, por terra, da Colônia do Sacramento até Laguna. O que é recorrente na sua crônica é a indicação dos rios Tramandaí e Mampituba como obstáculos naturais à passagem dos viajantes:

\footnotetext{
${ }^{1}$ É importante destacar que a proposta do autor encontra-se dentro do período de 1605 a 1801, portanto, existe uma série de crônicas de viagem que não estão dentro dessa proposta de periodização, como por exemplo, Saint-Hilaire, Arséne Isabelle, Nicolau Dreys, etc.
} 
Passando o Rio Grande se seguirá jornada sempre pela praia até chegar ao rio a que chamam Taramandabum (Tramandaí), o qual se passa a vau com água pela cinta em maré vazia, e pelo mesmo se vai continuando o caminho até chegar ao rio Iboipitiuhi (Mampituba); que com maré vazia se passa também a vau com água pela cinta. (CÉSAR, 1981[FILGUEIRA, 1703], p. 58-59)

Não há evidencias de grupos de pescadores estabelecidos no litoral norte do Rio Grande do Sul durante o período. Apenas é possível notar que, após o "desaparecimento" dos indígenas da região, sendo escravizados por bandeirantes, ou fugindo deles para o interior, não houve relatos de pescadores fixados na região, contribuindo para o abandono do local no período.

O terceiro período é marcado pela fundação do Rio Grande de São Pedro, através do relato de Cristovão Pereira de Abreu, que, segundo ele:

Como aqui não há farinha, nem pão, nem outro gênero de legume mais que a carne se extrai muita o que podia suprir a muita abundância de peixe que há nesse Rio (Rio Grande) se houvesse meios de o pescar pelo o que mando a Laguna comprar uma rede, mas sempre se faz preciso alguma providência de forma principalmente quando chegar a gente, porque o peixe não sofre tanto a falta dela como a carne. (CÉSAR, 1981[ABREU, 1737], p. 96)

Fica evidente, através do relato, que a pesca não era um meio de sobrevivência apreciado pelos moradores do litoral do Rio Grande de São Pedro. O fato de os habitantes da região não explorarem esse recurso indica uma desvalorização da carne do peixe. Além disso, a inexistência de artefatos, como as redes, também pode ter contribuído para a não prática da atividade, mesmo existindo matéria-prima em abundância na região.

O quarto período se inicia após a fundação do Rio Grande de São Pedro, sendo conhecido como "Terra de ninguém a terra de MUITOS" (CÉSAR, 1981). A característica principal desse período é a consolidação do povoamento na região, portanto, a possibilidade de fixação de grupos de pescadores ao longo do litoral gaúcho passa a ser maior a partir deste período. O litoral começa a ser mais explorado por terra, caminho para as tropas e viajantes que tinham como destino a região do Prata:

O caminho da Costa do Mar é pelas praias, onde a areia molhada, aplanada com as ondas, se une e endurece tanto, como o mais duro terreno, por serem muito finas e próprias para isso. Nos três rios Araranguá, Mampituba e Tramandi, estão guardas para averiguar as passagens e passaportes e se os gêneros ou couros tem pagos os direitos. No Tramandi se paga a passagem dos 3 rios. (CÉSAR, 1981[ROSCIO, 1781], P. 162-163) 
Mesmo com início da exploração contínua do litoral gaúcho, não se verifica a presença de pescadores nessa região, indicando que a pesca ainda não representava um meio de vida importante para os exploradores. Inclusive entre os soldados presentes nas guarnições dos rios, não há relatos de consumo da carne de peixe, evidenciando a ausência da pesca na região.

Com isso, pode-se afirmar que, desde o primeiro período, a pesca não representou um modo de subsistência importante para a manutenção das pessoas que circulavam pela região ou até mesmo moravam nela. Ela passou a ser mais difundida no litoral a partir do século XIX com a ocupação permanente do território rio-grandense, tornando o local um dos principais caminhos de acesso ao Rio Grande de São Pedro.

\section{Os relatos de viagem do século XIX e o surgimento dos grupos de pescadores no litoral gaúcho}

A partir do século XIX, inúmeros relatos de viagem foram feitos sobre o litoral do Rio Grande do Sul. Através desses relatos, foi possível retirar informações importantes sobre o desenvolvimento da pesca no litoral gaúcho, assim como, identificar os primeiros grupos de pescadores e os locais onde se estabeleceram. Entre esses depoimentos de viagem, destacam-se: o de Auguste de Saint-Hilaire, que passou pelo litoral norte do Rio Grande do Sul em 1820; o de Arsène Isabelle (1833-34), que fez algumas observações sobre a pesca em Rio Grande e São José do Norte; o de Nicolau Dreys (1839), que durante sua passagem em Rio Grande, também fez observações sobre o recurso pesqueiro abundante e a sua não utilização. Já no século XX, destacam-se os relatos de Edgard Roquette-Pinto, que contribui para uma compreensão do contexto lagunar do litoral norte no início do século, assim como o trabalho de Fernandes Bastos, em 1935, abordando a mesma região. Desse modo, , através desses autores é possível remontar a história da pesca, assim como o seu desenvolvimento no litoral norte do Rio Grande do Sul.

O primeiro relato fundamental para compreender o desenvolvimento da pesca no litoral norte do Rio Grande do Sul, por sua vez, foi o de Saint-Hilaire (1987[1820]). Percorrendo toda a extensão deste litoral, o autor descreveu aspectos relevantes, como, por exemplo, o meio ambiente litorâneo, bem como os locais onde havia abundância de peixe; os pescadores de Tramandaí, seus utensílios de pesca e suas residências e hábitos.

Ao longo de sua viagem, Saint-Hilaire descreveu o litoral como um local inóspito e monótono, pois a paisagem em determinados contextos era sempre a mesma, "areia branca a perder de vista”. Entretanto, nesta época, já existia uma ocupação da região, mesmo que 
pequena, caracterizada pelas sesmarias distribuídas pelo Rei, como, por exemplo, a estância do meio e o sítio do Inácio, que encontravam-se entre Torres e Tramandaí. Ao chegar a Tramandaí, Saint-Hilaire descreveu a região da seguinte forma:

O aspecto da região que percorremos hoje é o mesmo de sempre; o terreno plano e arenoso continua a apresentar pastagens entremeadas de capões e cobertas de uma erva espessa e amarelada. De vez em quando, percebemos, através da mata, trechos do lago, mas depois do Sítio do Inácio, as montanhas se distanciam e tomam a direção sudoeste. (SAINT-HILAIRE, (1987[1820], p. 1617)

Através do relato é possível afirmar que a viagem foi feita pela estrada da laguna, uma das principais rotas dos tropeiros durante o século XVIII (SANTOS, 2005), pois a ideia de que se tratava de um lago que percorre todo o litoral foi equivocada na época. Atualmente, sabe-se da existência de uma série de lagoas que são interligadas por canais de ligação e deságuam no mar através do canal de Tramandaí (VILLWOCK; TOMAZELLI, 1995). Outro exemplar importante a se destacar é o sítio do Inácio, pois, dentro dessa área, encontra-se, atualmente, a Barra do João Pedro.

Além disso, a descrição das moradias e dos utensílios de pesca, encontrados na sua passagem por Tramandaí, indicam um local importante para o desenvolvimento da atividade no litoral norte do Rio Grande do Sul:

Chegamos até o Rio Tramandaí, mas como fosse muito tarde, somente amanhã atravessaremos. Achamos, à margem desse rio, uma espécie de choupana, coberta de caniços, onde se amontoam umas doze pessoas, e junto a qual existe um pequeno galpão que serve de abrigo a canoa; [...] (SAINT-HILAIRE, 1987[1820], p. 17)

Ao longo do relato do autor, foi possível observar que Tramandaí representava uma área de pesca importante para os moradores da região. Isso porque, o peixe encontrava-se em grande quantidade, devido à ligação da lagoa com o mar, que possibilitava a entrada de espécies, como a tainha e, principalmente, o bagre. Outro aspecto que indica a relevância de Tramandaí para a pesca é o deslocamento sazonal de pessoas para pescar na área. Saint Hilaire destaca a questão em uma passagem de seu relato:

[...] Dos homens que ontem conheci, só um morava efetivamente ali; os outros são amigos e compadres que voltam de uma festa nas vizinhanças. Passam o dia todo se aquecendo, cozinhando e comendo peixes. [...] Disse-me o meu guia 
que possuía outra casa, com plantações, mas que vem aqui de tempo a tempo, devido à abundância da pesca. (SAINT-HILAIRE (1987[1820], P. 18-19)

Esse deslocamento sazonal de pescadores para a região, possivelmente, represente o primeiro núcleo de pescadores de maior relevância no litoral norte do Rio Grande do Sul. Ao longo das crônicas é possível observar que a região de Tramandaí já era tomada como um local estratégico para a fixação de um núcleo populacional. Portanto, a ocupação sazonal dos pescadores viabilizou uma permanência na região a partir do final do século XVIII (SOARES; PURPER, 1985).

Passados alguns anos da viagem de Saint-Hilaire, Nicolau Dreys, um comerciante francês que passou pelo Rio Grande do Sul em 1839, também registrou algumas observações que fez ao longo de sua viagem. Pode-se citar, entre elas, o desprezo do povo rio-grandense pela carne do peixe, a existência de pescadores nas regiões de Mostardas, no litoral central e no rio Camaquã, assim como o registro de algumas espécies que observou nessas regiões.

É possível observar que o relato de Dreys (1990[1839]) iniciou-se com uma consideração sobre o hábito do povo rio-grandense e seu desprezo pelo peixe:

As águas doces ou salgadas do Rio Grande abundam em peixe e, todavia, os habitantes parecem fazer pouco uso deles; vimos muitas vezes, depois do vento sul soprar com violência, a praia de Mangueira, na entrada de Rio Grande, ficar coberta de miraguaias, lançadas em terra pelas ondas, sem que a ninguém lembrasse mandá-las apanhar, nem sequer para os escravos. Geralmente, o habitante do Rio Grande não é ictiófago. (DREYS, 1990[1839], p. 59)

De modo geral, pode-se observar que a exploração dos recursos pesqueiros não se dirige ao consumo alimentar, sequer para complementar a dieta da população local. Em outra passagem de seu texto, o autor descreve a utilização das ovas da tainha e fala, também, do peixe seco, que é embrulhado e exportado para outras regiões, fora da província.

Assim, pode-se perceber que existe uma produção pesqueira voltada para o mercado externo, que não foi registrada, por exemplo, na passagem de Isabelle, em Rio Grande, anos antes. Essa diferença entre as duas fontes pode gerar distorções na busca de uma origem dos grupos de pescadores no litoral, sendo necessário considerar a relevância da subjetividade do enfoque de cada autor, assim como, pode-se analisar outras obras publicadas na mesma época para fazer um comparativo.

Outro aspecto presente no relato de Dreys é a descrição das espécies mais abundantes na região: 
Depois da miraguaia, um dos peixes que mais ordinariamente se oferecia à nossa vista é o bagre, igualmente desprezado; verdade é que, não obstante, existem ou têm existido na província algumas pescarias, a saber: uma de miraguaias, na lagoa de Mostardas; uma do mesmo peixe e bagres, na embocadura do Camaquã, na lagoa dos Patos, e uma de camarões, na praia do Rio Grande, dependente da vila de São José do Norte; na barra mesma do Rio Grande pescavam-se anualmente algumas tainhas, para extraírem-lhe as ovas [...] (DREYS, 1990[1839], p. 59)

Pode-se observar, como visto anteriormente, que o pescado não tinha como destino a alimentação da população local, mas o mercado de outras províncias. Além disso, nota-se que existe uma indefinição das origens dos grupos de pescadores no litoral do Rio Grande do Sul, visto que, as fontes vistas até então indicam que Tramandaí, assim como a região de Rio Grande, representam duas áreas que concentram as maiores possibilidades de desenvolvimento de grupos pesqueiros no litoral gaúcho.

\section{A chegada dos veranistas, o surgimento dos balneários e o desenvolvimento da pesca comercial no século XX}

A partir do início do século XX, a pesca no litoral norte do Rio Grande do Sul entra em um período de crescimento e afirmação. Diferente dos relatos vistos anteriormente, em que se pode notar uma sazonalidade da pesca na região de Tramandaí (SAINT-HILAIRE, 1987[1820]), os relatos do início do século XX indicam a existência de um grupo de pescadores fixos na região. A exploração do recurso pesqueiro era feita de forma intensiva, ao longo do ano, podendo-se notar a predominância do bagre, indubitavelmente, a espécie mais abundante na região de Tramandaí (SOARES, 2008).

Nesse período, é possível observar, através do relato de Edgard Roquette-Pinto, esse novo contexto de crescimento e afirmação dos pescadores no litoral norte, principalmente na região de Tramandaí. Passando pela região em 1906, o autor fez uma série de observações importantes, como a descrição da pesca de cerco do bagre, o comércio de produtos entre as colônias de agricultores da encosta da serra com os pescadores, a ausência de grupos de pescadores ao longo das lagoas e de canais do litoral e a formação de alguns balneários litorâneos, vitais para o desenvolvimento de uma pesca comercial intensa. 
Como visto anteriormente, a pesca de cerco do bagre foi a principal prática de pesca aplicada em Tramandaí. Roquette-Pinto descreveu essa prática de forma minuciosa, atento aos detalhes e aos conhecimentos aplicados pelos pescadores nessa pesca:

A emenda é uma companhia de 15 pescadores. [...] Formam nela quatro canoas; duas canoas de bater, com dois homens cada um, e duas canoas de rede, com cinco. Um capataz, homem prático em conhecer os cardumes pelas ondulações da superfície d'água, dirige a emenda. $\mathrm{Na}$ pescaria as canoas vão silenciosamente; quando o capataz faz o sinal de cardume, abrindo os braços, as portadoras da rede abrem-na também, cada uma indo para o seu lado, estendendo-a, assim em círculo. As outras canoas começam, então, a enxotar o peixe, batendo os homens com os remos de encontro aos bordos, num grande ruído. (ROQUETTE-PINTO (1962[1906], p. 22-23)

Essa descrição precisa do modo como se fazia a pesca do bagre, na época, é importante para a compreensão da organização do trabalho dos pescadores. Ainda segundo o autor, essa "emenda" era composta por um chefe, que era o dono do material de pesca e responsável pela exportação do peixe seco para outras regiões. Assim, iniciava-se, nessa época, uma indústria da pesca no litoral norte.

Outro aspecto destacado pelo autor é o processamento do peixe. Toda essa etapa descrita é voltada para o peixe de exportação, pois não há referências do peixe voltado para o consumo dos próprios pescadores. O relato do autor, nesse aspecto, é novamente minucioso:

Recolhida a rede são os bagres decapitados pelos pescadores e levados ao tendal, onde bandos de raparigas o escalam a salgam, entre risadas e cantigas. $\mathrm{O}$ bucho, bexiga natatória, é entregue aos pequenos, tradicionalmente chamados de guris no Rio Grande do Sul. Nem sempre o aproveitam. Posto a secar o bagre fica lembrando o bacalhau, que o Brasil tanto importa. É comprimido em grandes e primitivas prensas de madeira e enfardado depois. [...] em cada fardo são exportados 75 quilos de bagre; [...] muitas vezes é vendido como se fora bacalhau para o estrangeiro. (ROQUETTE-PINTO, 1962[1906], p. 23)

Após esse processamento do peixe, o autor descreve o descarte das carcaças e observa um fenômeno interessante, que é descrito como a formação de um sítio arqueológico. Esse processo ocorre devido à grande aglomeração de cabeças de bagre, que se amontoavam em uma ilha, próxima a entrada do rio Imbé, atualmente conhecido como rio Tramandaí:

Na entrada do rio Imbé há uma pequena ilha, onde existe um monte de cabeças de bagre rejeitadas pelos pescadores. Muitas são esqueletos já; as últimas, porém, aí depositadas, exalam um fétido cheiro que se pode imaginar. [...] A 
ilha cresce; será futuramente um enorme Kjökkenmödding². (ROQUETTEPINTO, 1962[1906], p. 25)

Depois de todo o processo mencionado, a maioria do pescado segue para Porto Alegre, com destino à exportação. No entanto, uma parte desse pescado é trocado com os moradores da encosta da serra por outros produtos da terra, como o milho, a mandioca e o feijão. Esse comércio desenvolveu-se ao máximo durante a década de 1960, quando a navegação lacustre era intensa no litoral norte do Rio Grande do Sul (SOARES, 2008).

Ao longo de sua viagem pelas lagoas do litoral norte, passando pelos canais e rios que ligam as lagoas, Roquette-Pinto não relatou a existência de nenhum grupo de pescadores instalados ao longo de seu caminho. Sendo assim, deve-se considerar, também, a possibilidade de grupos sazonais de pescadores na região, seguindo o modelo descrito por Saint-Hilaire no século XIX, quando os pescadores, em determinadas épocas do ano, deslocavam-se para a região de Tramandaí para aproveitar a abundância de peixe. A partir dessa hipótese, considera-se que na ocasião da passagem de Roquette-Pinto pelo litoral norte, ainda não existiam grupos de pescadores fixados ao longo das lagoas e canais.

Outro relato que contribuiu na construção da ideia da inexistência de grupos de pescadores na região lacustre é o de Fernandes Bastos (1935). Ao longo de sua viagem, passando pela localidade conhecida como Cornélios, o autor não fez nenhuma referência aos pescadores da região. Atualmente, a comunidade de Cornélios possui um núcleo considerável de pescadores, que atende o mercado de Capão Novo, Arroio Teixeira e Terra de Areia.

A partir do final do século XIX, iniciou-se, no Brasil, o fenômeno da vilegiatura marítima, que consiste de um modo geral, em práticas voltadas ao cuidado da saúde corporal através de banhos de mar e de sol (SCHOSSLER, 2010). Essas novas práticas passaram a vigorar, no Rio Grande do Sul na mesma época, deslocando, durante o verão, diversas pessoas para as estações balneárias do litoral norte. No entanto, sabe-se, através dos diversos relatos vistos anteriormente, que o litoral norte era uma região inóspita e de difícil acesso, onde a sobrevivência era dificultada pela ausência de solos férteis e, muitas vezes, pela falta de água potável, como descreveu Roquette-Pinto em sua passagem por Cidreira, rumo a Tramandaí:

Na praia de Cidreira não se vê a menor vegetação. Diante do mar, aí sempre muito batido, no imenso areal, erguem-se umas 20 choupanas de madeira, cobertas de palha, onde, nos meses de verão, algumas pessoas de Porto Alegre vem habitar, trazendo consigo o indispensável a vida. [...] A cobertura dos tetos

\footnotetext{
${ }^{2} \mathrm{O}$ termo é de origem dinamarquesa, e remete aos sítios arqueológicos com "restos de cozinha”, caracterizando um local de atividade humana.
} 
meio levantada pelo vento, as portas desconjuntadas, batendo livremente, davam ao lugarejo, onde nem água potável existe, o mais desolador aspecto. (ROQUETTE-PINTO (1962[1906], p. 18)

Nesta época, quando não havia meios de sobrevivência no litoral, com exceção de Tramandaí e de Torres, os veranistas deslocavam-se juntamente com todas as provisões necessárias para a sua permanência na praia. Schossler (2010) denominou essa época como "fase heroica" da vilegiatura marítima, pois, além da falta de recursos, existia uma dificuldade muito grande de deslocamento para essas regiões. As estradas eram péssimas e, em alguns casos, nem existiam. Alguns relatos da época confirmam a dificuldade que os veranistas encontravam para se deslocar até o litoral, assim como a descrição de Soares:

Inicialmente viajavam em carretas de bois. Mais tarde em carroções puxados por parelhas de cavalos. Organizavam-se em caravanas por causa das dificuldades da viagem. Não havia estradas. Apenas caminhos. Viajavam acompanhados de guias que conheciam a região. De Porto Alegre e do vale dos Sinos até Tramandaí, levavam uns oito dias de viagem. [...] A viagem era uma verdadeira aventura. Até onças encontravam pelo caminho. Precisavam trazer de tudo. [...] Havia carretas de carga, exclusivamente para transportar os mantimentos e todas as tralhas necessárias. (SOARES, 2008, p. 35):

Esse deslocamento se agrava para os balneários de Torres, que, na época, eram frequentados pelos moradores da região serrana do Rio Grande do Sul (SCHOSSLER, 2010). A viagem tornava-se mais perigosa, pois os caminhos da serra até o litoral eram compostos por atalhos, muitas vezes próximos a desfiladeiros muito altos, dificultando o deslocamento das famílias, que desciam ao litoral com seus suprimentos em carretas puxadas a boi. Segue o relato de uma viagem dado a Festugato:

Tinha lugares que era quase de em pé. Se descia com muita dificuldade. [...] Havia lugares tão apertados que não permitiam a passagem de dois animais. E eram precipícios que não se enxergava o fundo. Na travessia do rio Tainhas ${ }^{3}$ tínhamos que dar uma volta imensa porque havia dois panelões fundos. (FESTUGATO, 1994, p. 18-19):

Portanto, essa fase "heroica" dos primeiros veranistas no litoral norte ficou marcada pelas dificuldades de acesso à região. Na medida em que o número de pessoas que se deslocavam para o litoral começou a crescer, foi necessário o desenvolvimento de uma infraestrutura capaz de receber esses veranistas e possibilitar o mínimo com relação às necessidades básicas humanas

\footnotetext{
${ }^{3}$ Este rio encontra-se entre São Francisco de Paula e Itati, atualmente é conhecido como Rio do Pinto.
} 
para a permanência no local. O desenvolvimento dos balneários coincide com o surgimento dos hotéis e pousadas. É possível observar que, ao longo da origem de cada balneário, existia um estabelecimento de pouso, seja um hotel ou uma pousada, que viabilizou a permanência dos veranistas na região, como o Hotel Sperb em Tramandaí, o Hotel Bonfílio em Capão da Canoa e o Hotel Picoral em Torres. Soares e Purper destacam a importância dos hotéis no início do século XX:

Em 1898, estabelece-se aqui, o Sr. Jorge Enéias Sperb, inaugurando o Hotel Sperb, construído de madeira e coberto de palha. Nesse mesmo ano, instala-se o sistema de diligências, puxadas a cavalo que traziam e levavam os hóspedes (veranistas) entre Porto Alegre e Tramandaí. É preciso atrair o turista, por isto, além de oferecerem as diligências para a viagem, levam-nos de carreta para tomar o banho de mar. (SOARES E PURPER, 1985, p. 60)

Da mesma forma como ocorrido em Tramandaí, Capão da Canoa, conhecida, inicialmente, como Arroio da Pescaria, também teve um hotel no começo de sua formação. O Hotel Bonfílio possuía uma estrutura simples, mas recebeu alguns veranistas vindos da serra e de Porto Alegre. Logo após, foi criado o Hotel Pedro Nunes, que possuía uma estrutura mais elaborada para receber os veranistas, contando já com telhas de barro e com diligências periódicas, que traziam suprimentos da encosta da serra, como por exemplo, o milho, a mandioca, a banana, etc. (SANTOS, 2005).

O caso de Torres segue o mesmo exemplo, pois, com a chegada cada vez maior de veranistas, os hotéis começaram a surgir para suprir a demanda de pessoas que se deslocavam para o litoral durante o verão.

No início do século XX, a praia de Torres também foi contemplada com um empreendimento hoteleiro, do filho de imigrantes José Antônio Picoral.[...] Em dezembro de 1915, o Balneário Picoral foi inaugurado. Para o acesso a Torres foram providenciadas diligências que partiam de Tramandaí. Em suas primeiras publicidades na imprensa gaúcha, o hotel informava sobre o serviço de diligências, abertura da temporada de veraneio e serviço de cama e mesa. (SCHOSSLER, op. cit., p. 160)

É importante destacar que o desenvolvimento dos hotéis conduziu uma série de mudanças no litoral norte. Entre essas mudanças, podemos destacar o desenvolvimento de empregos, o consumo de bens materiais e, até mesmo a criação de restaurantes que, futuramente, garantiria o surgimento de uma pesca voltada ao consumo dos veranistas. Contudo, é necessário salientar o novo papel que os empreendimentos hoteleiros vão assumir nos balneários, segundo Schossler (2010), esses hotéis vão desempenhar um papel político para a formação das cidades 
do litoral, assim como contribuíram para o desenvolvimento do comércio e o aumento do consumo de pescado.

Passada essa primeira fase "heroica" de deslocamento para o litoral, a partir da década de 1910, algumas mudanças começaram a ocorrer no litoral norte do Rio Grande do Sul. A primeira delas é surgimento de novos meios de transporte para a praia. Esses novos meios facilitaram o deslocamento até os balneários, evitando as viagens exaustivas, assim como possibilitou o escoamento dos produtos da encosta da serra até os balneários e Porto Alegre.

O desenvolvimento da navegação lacustre, sem dúvida, acelerou o processo de crescimento dos balneários marítimos. A partir da década de 1910, iniciou-se uma série de obras hidráulicas, que tinha por objetivo a passagem de embarcações maiores pelos canais e lagoas do litoral norte. Conforme afirma Silva (1985), a navegação lacustre já é uma prática antiga no litoral norte, pois desde o início do século XIX, alguns moradores da encosta da serra utilizavam os canais e lagoas como transporte para suas mercadorias. No entanto, era uma navegação de embarcações pequenas e movidas a vela e remo:

A falta de comunicações entravava o progresso da região, pois condições geográficas, climáticas e populacionais existiam. [...] Por volta de 1847, já se tinham notícias de que usavam a via lacustre, singrando-se as lagoas situadas ao pé da Serra Geral até a lagoa da Pinguela. Dali, em carretas puxadas por cinco a seis juntas de bois, atravessavam os extensos campos de Conceição do Arroio, Santo Antônio da Patrulha, chegando, finalmente, em Porto Alegre. (SILVA, 1985, p. 44)

No entanto, a autora destaca que eram recorrentes as reclamações sobre os preços altíssimos cobrados pelos carreteiros e barqueiros, que levavam as mercadorias até os locais estabelecidos. Outro ponto que dificultava a navegação, além dos preços, era a ausência de obras hidráulicas, que viabilizassem o acesso de embarcações maiores na região. A autora frisa, ainda, as dificuldades encontradas para a navegação no final do século XIX:

Em Conceição do Arroio, canoas e pequenos barcos a vela singravam uma lagoa e outra até onde era possível. O junco e os baixios dificultavam a passagem pelos canais. Arrecadavam os produtos cultivados nas redondezas, pela via lacustre, para depois, transportá-los em carretas até a capital. [...] Nos primeiros tempos, mais importavam que exportavam, trazendo aos seus lares os produtos que faltava. Enfim, uma navegação lacustre precária, a nível particular, conforme suas necessidades. (SILVA, 1985, p. 54)

Dessa maneira, as obras hidráulicas começaram a ser implantadas na década de 1910, com os estudos topográficos nos canais e nas lagoas. Esses estudos continuaram até o final da 
década de 1920, época em que diversos aspectos foram pesquisados, entre eles, o regime de ventos do litoral, a topografia das lagoas e dos canais. Além disso, foram realizadas sondagens geológicas com o objetivo de conduzir os canais de modo que facilitassem sua abertura.

As melhorias na navegação possibilitaram uma redução no tempo de viagem, no caso dos veranistas e, também, no transporte de um volume maior de mercadorias. Porém, foram feitos investimentos em outros meios de transporte, como é o caso da atual rodovia RS-030, que costeia o pé da serra, fazendo a ligação entre Porto Alegre, Santo Antonio da Patrulha, Conceição do Arroio e Tramandaí.

Uma das obras hidráulicas de maior destaque na época e que modificou a paisagem do litoral foi a fixação da barra de Tramandaí. A obra contou com o apoio do governador do Estado Borges de Medeiros, que, juntamente com o intendente de Conceição do Arroio, Manoel Estevão Fernandes Bastos, iniciou, em 1913, as obras na barra.

Silva destacou a importância dessas obras e seus efeitos no litoral norte:

É importantíssima a fixação dessa barra, não só para a vida dos pescadores, que ficam sem trabalho, quando não entram peixes de água salgada, como também os proprietários de campos, até o sul da lagoa Itapeva, por perderem o escoadouro das águas das enchentes que lhes matam grande parte da criação durante o inverno. [...] Hoje se considera importante a construção dos moles de Tramandaí, favorecendo o escoamento das águas, entrada de embarcações de considerável calado e, principalmente, servindo de quebra-mar, imagine-se sua importância, naquela época, em termos de dinâmica de embarcações, de facilidades que dela resultariam. (SILVA, 1985, p. 75-76)

Portanto, pode-se afirmar que as obras em Tramandaí possibilitaram o desenvolvimento de obras seguintes, ao longo das lagoas e canais. Além disso, proporcionou uma melhoria de vida dos pescadores da região, pois, a entrada dos peixes de água salgada passou a ser contínua ao longo de todo o ano, aumentando a produção do pescado. Sendo assim, nessas duas primeiras décadas do século XX, a navegação lacustre foi pensada como uma alternativa para o desenvolvimento do litoral norte, através das obras hidráulicas que começaram a ser implantadas nessa época. Após o desenvolvimento de alguns portos, ao longo das lagoas e canais, iniciou-se um fluxo intenso de embarcações de maior porte, até mesmo balsas motorizadas, que faziam a rota comercial entre a Conceição do Arroio e Torres.

A partir de 1926, após a inauguração de diversos portos nas lagoas do litoral norte, foi criada uma rota comercial, composta por um caminho lacustre, de Torres à Conceição do Arroio, um caminho terrestre, de Conceição do Arroio a Palmares do Sul, seguindo, novamente, de barco até Porto Alegre. As referidas obras possibilitaram o desenvolvimento dessa rota comercial, 
favorecendo os habitantes dos balneários, da encosta da serra, além de os veranistas. Conforme Silva (1985), os últimos foram beneficiados pela grande circulação de gêneros alimentares, que possibilitou uma permanência mais longa nos balneários e facilitou seu deslocamento, pois já não era preciso levar os alimentos necessários para a permanência no litoral, tornando as viagens mais rápidas. Ainda segundo a autora, os veranistas utilizavam, preferencialmente, o caminho terrestre, sendo o caminho lacustre, predominantemente, utilizado para o transporte de produtos.

O desenvolvimento dos portos foi rápido durante esse período, porque, em menos de uma década, formaram-se mais de oito, destacando-se: o porto da lacustre, situado em Conceição do Arroio. Esse porto recebia todos os produtos vindos de Palmares e de todos os outros portos, visto que fazia a transição entre transporte lacustre e ferroviário. Além disso, há o porto da Cachoeira, localizado em Maquiné. Conforme a autora, era o local mais promissor pois, nessa região, produzia-se alimentos como o arroz, o feijão, o café, o milho, etc. E, finalmente, o porto de Três Forquilhas, que também transportava os gêneros vistos anteriormente.

As rotas comerciais das lagoas, assim como as terrestres, encontravam-se todas direcionadas a Porto Alegre. Esses portos trouxeram o desenvolvimento para as regiões mais afastadas do litoral norte, bem como contribuíram para o crescimento da atividade pesqueira na região. Pode-se afirmar que o crescimento dessa atividade está vinculado ao aumento do comércio de peixe com outras regiões, o que também contribuiu para a transformação das práticas de pesca, como, por exemplo, a pesca de espécies de alto valor de mercado, a especialização de alguns pescadores voltados à pesca de exportação, como é o caso do bagre, a própria comercialização do peixe, que, anteriormente, servia quase que completamente para a subsistência.

Segundo Muri, o porto da Lacustre trouxe o progresso ao litoral norte. Além do aumento do transporte de pessoas, houve um crescimento incalculável de produtos que circulavam e passavam por esse porto:

[...] e pelos anos 40, com o desenvolvimento das praias balneárias, muitos barcos seguiam direto para Tramandaí e Capão, a esta, pela Barra do João Pedro. [...] Com toda essa produção tirada das colônias ribeirinhas, mais a presença de mercadorias importadas via Palmares, a prosperidade se generalizou, podendo-se notá-la pelo número de pensões que se abriram como resultado do intenso comércio que então se estabeleceu. (MURI, 1992, v.3, p. 75)

Destaca-se, ainda, a construção da linha férrea, ligando Palmares do Sul à Conceição do Arroio, em novembro de 1922, que, como visto anteriormente, faz parte da rota comercial Palmares do Sul - Porto Alegre. A utilização dessa linha possibilitou um aumento da quantidade 
de produtos que se dirigiam a Porto Alegre, mas para que isso fosse possível, foi necessária a utilização de embarcações de maior porte. Por este motivo, houve a necessidade de manter a dragagem dos canais sempre em andamento, pois isso possibilitava a passagem de embarcações com maior calado.

Em época de safras, mais exportavam do que importavam de Palmares do Sul para a Capital. [...] Para que toda essa engrenagem pudesse manter-se organizada, estando sempre disponível todo o equipamento da navegação, estrada de ferro e, novamente, navegação, foi necessária a limpeza constante dos canais obstruídos por juntos e toda a espécie de materiais, reforma de embarcações e dragagens assim como a manutenção de pontes, da linha de ferro, trocando os dormentes e cuidando para que a areia não tomasse conta dos trilhos periodicamente. (SILVA, 1985, p. 91)

De modo geral, a manutenção desse sistema de comércio, que se estabeleceu entre o litoral norte e Porto Alegre, facilitou o acesso dos veranistas ao litoral, bem como viabilizou seu maior tempo de permanência na praia. Na medida em que existe uma melhoria dos meios de transporte, o litoral passava a se tornar uma região acessível aos deslocamentos sazonais dos produtos comercializados e das pessoas que o frequentam durante o verão.

Ainda durante a década de 1920, é possível observar um acontecimento interessante, a introdução de pintados na Lagoa dos Barros. Segundo Muri (1995, v. 4) alguns trabalhadores da linha férrea trouxeram de Palmares do Sul exemplares de pintados em grandes latas cheias d'água.

Mas quem, depois de 1925, pescasse na dita lagoa, que antigamente se chamava "Lagoa Formosa", iria puxar no seu anzol um peixe novo naquelas águas: era o "pintado", e tal se deveu ao trabalho do maquinista Marcelino e seus companheiros da locomotiva, cujos trilhos por ali passavam; [...] O propósito dos ferroviários era jogá-los na Lagoa dos Barros, para que se multiplicassem. E, assim, eles fizeram, na volta do trem para Conceição, repetindo o trabalho por várias vezes. [...] Foi por existir nossa ferrovia que hoje temos "pintados" na Lagoa dos Barros. (MURI, 1995, p. 14-15)

Portanto, é possível observar que a introdução de uma nova espécie no litoral norte é uma prática de pesca que pode ser datada, pelo menos no caso do pintado. No entanto, em diversos diálogos com os pescadores de João Pedro ${ }^{4}$, confirmou-se que não existiam pintados em sua

\footnotetext{
${ }^{4}$ Esses diálogos foram conduzidos diversas vezes, pois durante a pesquisa etnográfica realizada com este grupo, foi possível resgatar algumas informações importantes sobre o passado da região. Como esta pesquisa foi desenvolvida sob uma perspectiva etnoarqueológica, deve-se destacar que não seguiu os passos propostos pela história oral. (SILVA, 2012)
} 
área de pesca. Isso se deveu ao isolamento da Lagoa dos Barros em relação ao restante do complexo lagunar do litoral norte.

O surgimento de diversas empresas de condução auxiliou no deslocamento cada vez maior de pessoas para o litoral. Mesmo com a existência da estrada até Tramandaí, muitas empresas faziam o transporte até outras praias pela Beira Da Praia (SANTOS, 2005). No caso das praias mais ao norte, como, por exemplo, Capão da Canoa e Torres, as estradas chegaram ao final da década de 1960, com a conclusão das obras da BR-101.

À medida que aumentou o consumo de pescado, devido ao crescimento de veranistas no litoral, as práticas de pesca também foram se transformando, e, cada vez mais, voltando-se para uma pesca comercial de escala familiar. É possível observar esse processo de transformação nos diálogos com os pescadores, pois sempre fazem referência a uma pesca mais voltada ao consumo familiar, com raras exceções lembram-se de um fluxo intenso de venda de peixe, como o bagre seco, que era sabidamente exportado em larga escala para outras regiões.

Neste mesmo período em que se desenvolveram diversas empresas de condução, Capão da Canoa encontrava-se em pleno desenvolvimento, da mesma forma que Cidreira, Tramandaí e Torres. Esse balneário possui uma importância muito grande para o crescimento da comunidade de pescadores da Barra do João Pedro, pois é o principal centro de consumo de pescado da região, absorvendo, atualmente, quase toda a produção dos pescadores. É possível observar, em fotografias da época, a existência de pequenas casas de madeira próximas à balsa que havia na região.

O surgimento dessas empresas de condução, além de possibilitar o acesso ao litoral em um fluxo contínuo, também foi responsável pela entrada de novas embarcações na região. Inicialmente, para o transporte de mercadorias das colônias de Maquiné e Três Forquilhas para Tramandaí, essas embarcações a vapor ou motor de centro, aos poucos, foram substituindo as embarcações à vela e a remo, amplamente utilizadas até então (SILVA, 1985). Portanto, a utilização de motores, principalmente de centro ${ }^{5}$, nas embarcações de pesca, iniciou-se a partir dessas inovações tecnológicas trazidas pelos novos meios de transporte vindos da capital (DIEGUES, 2004).

A partir desse momento, juntamente com o surgimento das empresas de condução, surgiu a primeira empresa de loteamento de terra do litoral norte. Essa empresa, chamada Empresa Territorial Capão da Canoa Ltda. comprou uma grande extensão de terras na região, do mar até a

\footnotetext{
${ }^{5}$ Diferente dos atuais motores de popa, que são portáteis e ficam na parte traseira da embarcação, os motores de centro são fixados nela e localizam-se no centro desta. Segundo afirmam os pescadores da barra do João Pedro, os motores de centro gastam menos combustível e são mais duráveis, contudo, sua manutenção é mais cara.
} 
lagoa dos Quadros. Isso ocorreu em função do aumento de veranistas que começaram a frequentar Capão da Canoa e, após o loteamento das terras, muitos chalés de madeira começaram a surgir, indicando uma nova ocupação no litoral, quando os veranistas passaram a adquirir seus próprios imóveis (SANTOS, 2005).

O aumento de veranistas trouxe o aumento das construções de chalés de madeira. Muita gente duvidava das construções em alvenaria (de tijolos) devido ao solo arenoso. A Empresa Territorial iniciou a construção de cinco casas de alvenaria, sendo uma geminada. [...] Os loteamentos eram feitos baseados em uma planta urbana. (SANTOS, 2005, p. 84-86)

Ainda segundo a autora, após a venda dos loteamentos, foi criada a Construtora Capão da Canoa Ltda., que, no final da década de 1940, foi responsável pela construção do primeiro prédio do litoral, o edifício Aymoré, até mesmo a primeira calçada de paralelepípedos na Rua Pindorama (SANTOS, 2005). Com o aumento populacional, ocasionado por todos os fatores vistos, anteriormente, novas necessidades surgiam para a manutenção dos veranistas inclusive por parte dos moradores do litoral. Uma dessas necessidades era, principalmente, o abastecimento de água potável.

Nesse período, segundo a autora, iniciou-se um processo de crescimento da cidade que não seria mais revertido. Ao mesmo tempo, consolidava-se um mercado consumidor, que garantiria a sobrevivência dos pescadores no inverno, podendo-se, novamente, observar essa relação de dependência dos pescadores diante do restante da população litorânea. Neste período, a Barra do João Pedro começou seu crescimento ligado a Capão da Canoa, acompanhando as transformações que ocorriam na região. Essas mudanças podem ser observadas, na atualidade nas práticas de pesca sazonais, que no inverno estão voltadas a uma pesca para o consumo de moradores do litoral e no verão aos veranistas, que consomem outros tipos de pescado ${ }^{6}$.

Segundo Santos (2005), o abastecimento de água era feito por bombas movidas à energia eólica, semelhantes a cata-ventos, que bombeavam a água da lagoa dos Quadros até a caixa d'água. Esta ainda permanece de pé, em frente à prefeitura de Capão da Canoa. Já na década de 1950, iniciaram-se as obras da ponte sobre a Barra do João Pedro, pois o aumento do fluxo de viajantes obrigou as autoridades a substituir a balsa precária sobre tonéis.

A partir dessas melhorias implementadas no litoral, desde o início do século XX até os dias de hoje, os balneários litorâneos passaram a ter um crescimento constante até a atualidade. Além disso, o costume de frequentar a praia durante o verão continuou a ser uma prática muito

\footnotetext{
${ }^{6}$ Através das observações de campo, é possível afirmar que os moradores do litoral têm preferência por peixes de menor valor de mercado, como por exemplo, o bagre, o jundiá e o cará.
} 
difundida entre os gaúchos. Na medida em que ocorria esse crescimento da população no litoral, o consumo de produtos da região também cresceu, como por exemplo, o peixe, que possivelmente impulsionou a fixação das comunidades de pescadores em regiões próximas aos núcleos urbanos.

Segundo algumas informações obtidas em conversas com os pescadores da Barra do João Pedro, quase toda a sua produção é destinada ao mercado consumidor de Capão da Canoa, desde hotéis, restaurantes, quiosques na beira do mar, etc. Sendo assim, é possível afirmar que o desenvolvimento das comunidades está intimamente ligado ao crescimento dos balneários litorâneos e com a chegada dos veranistas. E, isso se revela um fato interessante, pois, no caso dos quiosques à beira mar, o peixe consumido não é de origem marinha, mas das lagoas, o que contribui para a hipótese acima referida.

A partir das inovações tecnológicas introduzidas e com o crescimento do mercado consumidor, pode-se observar que a pesca torna-se cada vez mais mercantil (DIEGUES, 2004), abandonando sua característica inicial de subsistência. Dessa maneira, é possível afirmar que, no século XX, o modo de vida dos pescadores começa a se alterar gradativamente, processo este que, atualmente, culmina na pesca especializada de determinadas espécies para o consumo dos veranistas (SILVA, 2012).

\section{Considerações finais}

Durante o período abordado na pesquisa, século XVII-XX, notou-se que a atividade pesqueira do litoral norte do Rio Grande do Sul foi marcada por poucas alterações do ponto de vista tecnológico, social e de consumo. Durante os dois primeiros séculos (XVII e XVIII), a pesca parece não ter representado uma importante forma de sobrevivência, pois sequer há relatos da utilização do recurso pesqueiro ou existência de grupos de pescadores na região.

No século XIX, a pesca ainda era uma atividade sazonal, ou seja, era realizada em períodos em que havia escassez de alimentos, muito semelhante aos caiçaras do litoral de São Paulo. Eles intercalavam a pesca com a agricultura e caça, utilizando os recursos próximos as regiões de mata (MARCÍLIO, 2006). Portanto, nota-se que a atividade pesqueira nestes três primeiros séculos era marcada pela ocupação e abandono da região costeira, assim como pela utilização da pesca como meio de vida. 
Já no século $\mathrm{XX}^{7}$, esse paradigma parece se alterar. $\mathrm{O}$ surgimento de um mercado consumidor em maior escala e a utilização de novas tecnologias, como, por exemplo, melhores canoas, motores e redes de nylon, alteraram o modo de vida desses pescadores. Assim, eles passaram de uma subsistência, que, por vezes, dava-se em função da troca de peixe por outras mercadorias, para o comércio do pescado, configurando o que Diegues (2004) denominou como pesca tradicional mercantil de pequena escala.

A partir disso, pode-se afirmar que o desenvolvimento da atividade pesqueira no litoral norte do Rio Grande do Sul vem de longa data. A longa duração desta atividade, mesmo com o período de dois séculos sem relatos sobre esta atividade, indica como é importante a pesca para a fixação de núcleos populacionais no litoral. Isso se verifica a partir do século XIX, quando os relatos já indicam a utilização deste recurso por alguns habitantes. E, isso se intensifica com a chegada dos primeiros "veranistas", os quais, no início do século XX, começaram a povoar, sazonalmente, as praias do litoral norte. Portanto, trata-se de compreender e valorizar a atividade pesqueira como um dos importantes fenômenos que deram origem à ocupação histórica do litoral gaúcho.

\section{REFERÊNCIAS BIBLIOGRÁFICAS}

BASTOS, F. Noite de reis: narrativa histórica. Porto Alegre: Globo, 1935.

CESAR, G. Primeiros cronistas do Rio Grande do Sul. Porto Alegre: Ed. da UFRGS, 2a . Edição, 1981.

DIEGUES, A.C. A Pesca Construindo Sociedades. São Paulo: NUPAB - USP, 2004.

DREYS, N. Notícia Descritiva da Província do Rio Grande de São Pedro do Sul. Porto Alegre: Nova Dimensão, 1990[1839].

FESTUGATO, E. Torres de Antigamente: crônicas e memórias. Caxias do Sul, 1994.

MARCÍLIO, M. Caiçara, terra e população. São Paulo: Edusp, $2^{\circ}$ edição, 2006.

MURI, G. Remembranças de Conceição do Arroio. Porto Alegre: Jollo, v. 3, 1992.

\footnotetext{
${ }^{7}$ Não há um marco objetivo para a alteração do modo de vida pesqueiro. A proposta delimita o século XX, pois a partir dos relatos apresentados por Roquette-Pinto e nos diálogos com os pescadores, nota-se que o processo iniciouse com a entrada de novas tecnologias e com um fluxo sazonal contínuo de consumidores se deslocando para o litoral.
} 
Remembranças de Conceição do Arroio. Porto Alegre: v. 4, 1995.

ROQUETTE-PINTO, E. Relatório de excursão ao litoral e à região das lagoas do Rio Grande do Sul. Porto Alegre: UFRGS, 1962[1906].

SAINT HILAIRE, A. Viagem ao Rio Grande do Sul. Porto Alegre: Martins Livreiro, 1987 [1820].

SANTOS, M. S. Origens de Capão da Canoa (1920-1950). Porto Alegre: EST Edições, 2005.

SCHOSSLER, J. C. "As nossas praias": os primórdios da vilegiatura marítima no Rio Grande do Sul (1900 - 1950). Dissertação (Mestrado em História) Programa de Pós Graduação em História-PUCRS, Porto Alegre, 2010.

SILVA, M. R. 1985. Navegação Lacustre Osório-Torres. Porto Alegre: Luzzatto Editores, 140 p.

SILVA, L. Pescadoras da Barra do João Pedro: um estudo etnoarqueológico. Dissertação (Mestrado em História) Programa de Pós-Graduação em História, PUCRS, Porto Alegre, 2012.

SOARES, L. S. Tramandaí - Imbé: 100 anos de história. Porto Alegre: EST edições, 2008. ; PURPER, S. Tramandaí: terra e gente. Tramandaí: AGE, 1985.

VILLWOCK, J. A.; TOMAZZELI, L. J. Geologia costeira do Rio Grande do Sul. Notas técnicas, Porto Alegre, n. 8, p. 1-45, 1995.

ARTIGO ENVIADO PARA PUBLICAÇÃO EM: 14.07.2013

ACEITO PARA PUBLICAÇÃO EM: 17.09.2013 